\title{
МЕТОД НЕПРЕРЫВНОГО МОНИТОРИРОВАНИЯ УРОВНЯ ГЛЮКОЗЫ В ОЦЕНКЕ ВАРИАБЕЛЬНОСТИ ГЛИКЕМИИ ПРИ ИСПОЛЬЗОВАНИИ АНАЛОГОВ ИНСУЛИНА ДЛИТЕЛЬНОГО И СВЕРХДЛИТЕЛЬНОГО ДЕЙСТВИЯ В ТЕРАПИИ САХАРНОГО ДИАБЕТА 2 ТИПА
}

\author{
'Берстнева С.В., ' Баранов В.В., 'Дубинина И.И., ${ }^{2}$ Кузин М.Н., ${ }^{2}$ Кузина К.М., ${ }^{1}$ Приступа М.А. \\ 'ФГБОУ ВО «Рязанский государственный медицинский университет им. акад. И.П. Павлова» МЗ РФ, Рязань \\ гГБУ РО «Областная клиническая больница», Рязань
}

ЦЕЛЬ: оценить вариабельность гликемии при использовании аналогов инсулина длительного и сверхдлительного действия в терапии больных сахарным диабетом (СД) 2 типа методом непрерывного мониторирования уровня глюкозы (НМГ).

МАТЕРИАЛЫ И МЕТОДЫ: обследовано 19 пациентов с СД 2 типа (м/ж - 8/11 чел.) Средний возраст $59,0(57,0 ; 62,0)$ лет, длительность СД - 9,0 (7,5; 10,0) лет, длительность инсулинотерапии - 6,0 $(2,5 ; 8,0)$ лет. Все обследованные получали инсулинотерапию в базал-болюсном режиме в сочетании с метформином (1000-2500 мг/сут.). Из них 1 группа - 11 чел., использовали в качестве базального компонента аналоги инсулина длительного и сверхдлительного действия (инсулин гларгин 100 ЕД/мл и 300 ЕД/мл, детемир, деглудек), 2 группа - 8 чел., получали инсулин НПХ. Группы достоверно не различались по возрасту, стажу СД, длительности применения инсулинотерапии. Всем пациентам проводилось общеклиническое обследование, определение уровня гликированного гемоглобина ( $\left.\mathrm{HbA}_{1 c}\right)$ и НМГ в течение 7 суток с использованием системы i-Pro2 Medtronic. Вариабельность гликемии анализировалась с помощью калькулятора EasyGV (version 9.0). Оценивалась среднесуточная гликемия (Mean), стандартное отклонение (SD), средняя амплитуда колебаний гликемии (MAGE), непрерывное частично перекрывающееся изменение гликемии (CONGA), индекс лабильности гликемии (LI), индексы риска гипо- и гипергликемии (LBGI и HBGI), средняя скорость изменения гликемии в течение суток (MAG).

РЕЗУЛЬТАТЫ: уровень НbА составил в 1 и 2 группе 7,85 (6,27;9,82) \% и 8,23 (6,13;9,34) \% соответственно ( $\mathrm{p}=0,8633)$. При анализе данных НМГ показатели среднесуточной гликемии (Mean) также достоверно не различались: 8,57 (7,20;11,03) и 8,76 $(8,09 ; 9,8)$ ммоль/л ( $\mathrm{p}=0,9686)$. Однако, в параметрах вариабельности гликемии выявлены достоверные различия: SD - 1,22 (0,98;1,33) и 2,99 (1,47;3,06) ммоль/л ( LI - 2,62 (2,01;4,67) и 14,02 (4,88;19,78) (ммоль/л) $/ 4$ ( ммоль/(л*час) ( $\mathrm{p}=0,006)$ в 1 и 2 группах соответственно. Отмечена тенденция к снижению показателя MAGE в 1 группе - 4,65 $(4,25 ; 5,55)$ и 7,5 $(5,4 ; 10,2)$ ммоль/л $(p=0,0875)$. Индекс LBGl, наиболее чувствительный к гипогликемии, был достоверно выше в 2 группе и составил $3,99(0,43 ; 9,94)$ усл. ед. в сравнении с 1 группой - 0,0 (0,00;0,34) усл. ед. ( $p=0,030)$. Гипогликемические состояния со снижением уровня глюкозы менее 3,9 ммоль/л отмечались у 3 пациентов 2 группы в ночное время, что скорее всего связано с особенностью профиля действия (наличие пика) инсулинов НПХ.

ВЫВОдЫ: применение аналогов инсулина длительного и сверхдлительного действия в качестве базального компонента базал-болюсной инсулинотерапии позволяет уменьшить вариабельность гликемии в течение суток и количество ночных гипогликемических состояний у пациентов с сахарным диабетом 2 типа.

КЛЮЧЕВЫЕ СЛОВА: непрерывное мониторирование уровня глюкозы; вариабельность гликемии; сахарный диабет 2 типа; аналоги инсулина длительного и сверхдлительного действия. 